\title{
A representação do espaço em textos fílmicos e literários da América Latina
}

\author{
ANNA MARIA BALOGH \\ (Vice-Coordenadora do Curso de Rádio e TV \\ na Escola de Comunicações e Artes da USP)
}

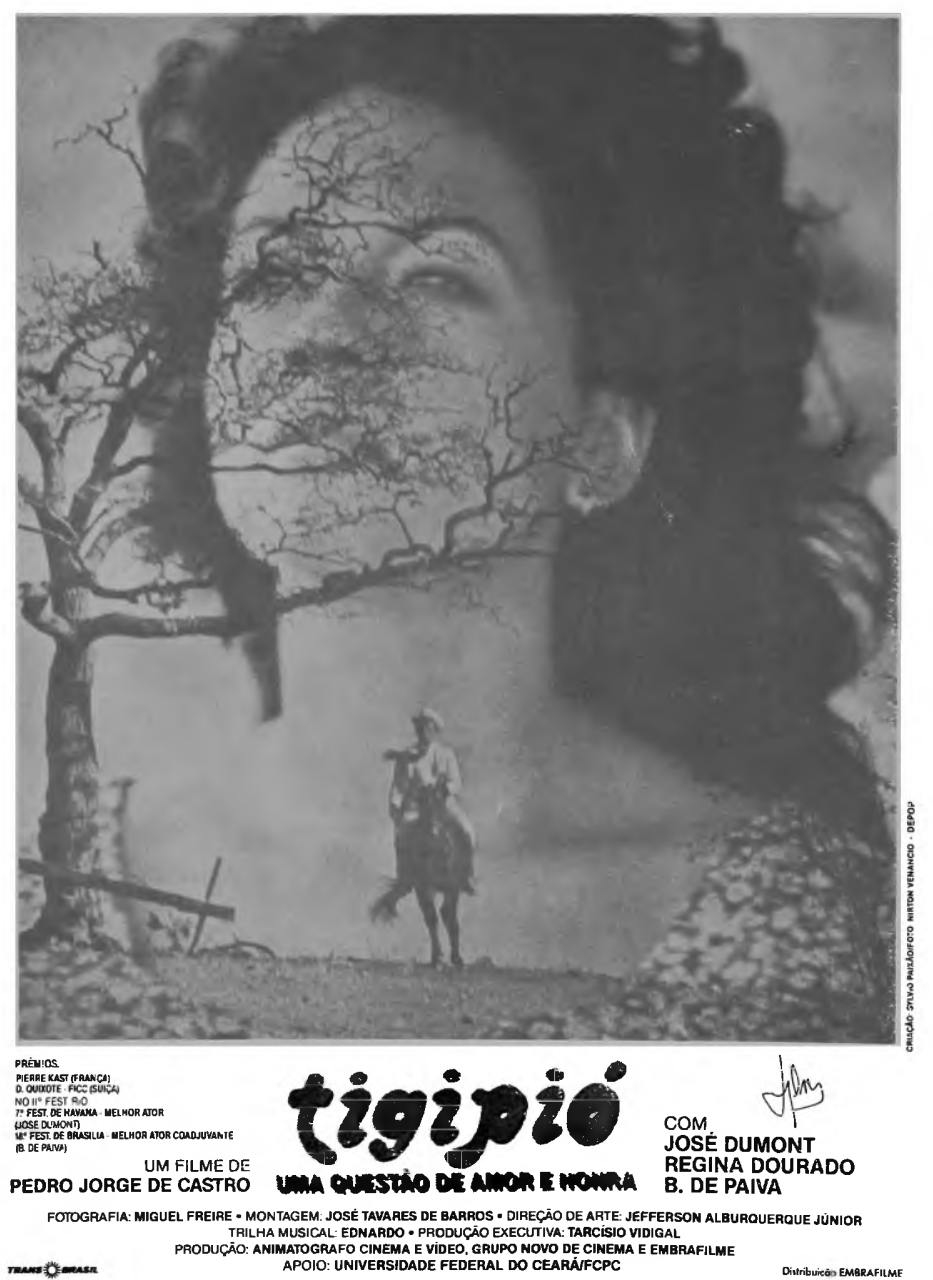


Podemos considerar a realizaçāo de um filme como sendo um processo cultural constituído de etapas que começa com a roteirização e termina com a recepção por parte do público e da crítica. Nas adaptaçóes, o texto literário torna-se pré-texto para o roteiro e acresce uma etapa ao processo.

Faremos aqui uma reflexāo sobre a representação do espaço nas etapas do fazer filmico. Daremos preferência a filmes latino-americanos adaptados de obras literárias por permitirem comparaçōes entre os textos. Quando se fizer necessário, utilizaremos obras literárias năo adaptadas e filmes com roteiro original.

Palavra e imagem são representação, existem "em lugar de"; voltamos às primeiras aulas da universidade. A palavra existe "em lugar de" um conceito e não de um objeto concreto, real; trata-se de um designatum, não de um referente. A literatura tampouco tem compromisso com o real, mas sim com o verossímil. Mas as liçōes da universidade são contraditórias, pois aprendemos também que bá uma literatura regionalista, classificação vinculada a parâmetros da realidade física, dividida geograficamente.

\section{A representação do espaço na literatura}

A leitura da ensaística e da fiç̧ão hispano-americanas permite traçar uma grande linha divisória no tocante à representação do espaço. No primeiro momento, nossos escritores tentam captar o que é 'típico' através de técnicas que enfatizam uma aproximação mimética ao real. $O$ texto se expande no descritivismo detalhista que pretende dar conta do espaço americano denotativamente em benefício de um pretenso realismo/autenticidade e em prejuízo da densidade e da função poética. No segundo momento, surge a consciência da impossibilidade de expressar a radical heterogeneidade étnica, temporal e espacial da América Latina atraves do denotado, do fotográfico. A ensaistica se avoluma, então, na busca de explicaçōes, e a ficção se transforma mediante o uso de novas técnicas de narrar, de representar o tempo e o espaço. Muitos escritores se dedicam à ficção e ao ensaio simultaneamente, recordamos os mais próximos a nós, como Paz, Carpentier, Fuentes, G. Márquez, e E. Sábato. $\mathrm{Na}$ obra destes e de outros autores hispano-americanos do segundo momento da nossa literatura, o espaço adquire valores conotados, isomórficos e simbólicos e representa uma revolução na narrativa e no discurso. A literatura latino-americana evolui do realismo/regionalismo para o tão decantado realismo mágico. (Bỉbliog. 4-5-6 e 7).

\section{A representação do espaço no cinema}

A crítica existente sobre o cinema latino-americano $\varepsilon$ bem mais dispersa e incipiente do que a literária. Há poucos filmes nossos passados ao vídeo; a distribuição e a comercialização também são preḉrias, dificultando o acesso às obras. Assim, não podernos afirmar se o cinema passou ou não por evolução similar à da literatura, mas podemos fazer algumas considerações sobre a forma de representar o espaço no cinema que podem ser esclarecedoras também no tocante à diacronia. 
No que diz respeito à concepçāo do espaço no cinema, o descarte puro e simples do concreto, do referencial à antiga, náo parece tão simples quanto na literatura. Uma das servidōes do cinema clássico é precisamente a de depender de um espaço concreto a ser filmado, ainda que a representação venha mediatizada pelos enquadramentos, angulaçōes e movimentos de câmera e pelos cortes e efeitos de moviola. Podemos dispor de um espaço real anterior à filmagem (locação/externa), de um espaço especificamente construído para uma filmagem $\mathrm{X}$ (cenários, externas ou internas $=$ estúdios), ou ainda de cenários reaproveitados de filmagens prévias.

A evolução na literatura se deuprimordialmente através da mudança na visão de mundo e da subversão nas técnicas de narrar da maioria dos escritores hispano-americanos. No caso do cinema, revolucionar parece bem mais difícil devido às razões que apontamos a seguir. $O$ filme é realização coletiva e nem o mais despótico dos diretores tem domínio total sobre sua obra. Condicionantes de produção filmica (orçamento, equipamentos, etc... interferem de forma muito mais poderosa na produçăo "semiótica" do sentido do que o leigo ou o crítico distanciado da realizaçāo possam imaginar. Pudemos comprovar esse fato nos casos em que tivemos acesso aos roteiros e notamos reconfiguraçōes ponderáveis nas etapas de passagem do texto literário para o roteiro, e deste, para o texto filmico. A forma de representação do espaço no filme não depende exclusivamente da competência do realizador, como na literatura. O cinema depende em muito maior grau da sofisticação dos equipamentos de filmagem e edição para viabilizar concepçōes do realizador do que qualquer outra forma de arte. Inútil imaginar soluçōes ou efeitos incríveis, sem dispor de lentes adequadas, de câmeras com recursos, de grua, de 'switcher' com boas possibilidades de efeitos e de um grande número de equipamentos sofisticados e caros.

A célebre frase "uma câmera na mão e uma idéia na cabeça", definidora do "cinema novo", parece anacrônica. Trata-se de uma estética válida para os anos 60 , com inúmeros filmes em $P$ \& B, próximos ao neorealismo italiano, coerentes com a precariedade dos meios de produção e a ideologia impulsora do movimento, mas insustentável três décadas depois.

O mercado cinematográfico brasileiro abarca atualmente produçōes caras, hollywoodianas como "Quilombo", de Cacá Diegues e produções muito restritas em termos de orçamento como "Tigipi6", de Pedro Jorge de Castro na qual participamos na fase de adaptaçāo/roteirização. Ao revermos obras da filmografia brasileira e da latino-americana (as que chegam até nos), verificamos que nenhuma delas retoma no cinema o rico veio do realismo mágico literário. A maioria das adaptaçōes que conhecemos teve condiçōes medianas de produção, mas nāo acreditamos que este seja o único fator determinante para a ausência apontada.

Quais são as representaçōes de espaço recorrentes na filmografia latino-americana? Em que medida a representação do espaço seria definidora de nossa "latinidade" ou "hispanidad"?

A importância da concepção/visualização do espaço já foi objeto das consideraçōes dos realizadores. Jorge Durán, roteirista de "Pixote" e 
de "Lúcio Flávio", afirma que "escrever um roteiro... é lidar com formas" e que "um roteiro pode ser lido, mas na verdade é visto." (Biblio.11, p.8). Na opinião do realizador francês, Godard, o espaço e fundamental:

"O cenário me ajuda a encontrar idéias. Muitas vezes, mesmo, é dele que eu parto.(...) Eu me pergunto se é possivel determinar a locação depois da redação do roteiro. É preciso pensar no cenário antes. Freqüentemente um sujeito escreve, "ele entrou no quarto", pensando num determinado quarto. $E$ o filme é feito por outro que pensa num outro quarto. Isso desiquilibra tudo. Não se vive da mesma maneira em cenários diferentes". (Bibliog. 11, p.19).

A busca de arquétipos espaciais no cinema nos remete também à literatura atravês das adaptaçóes. Um resgate nos guardados da memória nos leva a associar textos: "Vidas Secas", de Graciliano Ramos e Nelson Pereira dos Santos; "Grande Sertāo: Veredas", de Guimarāes Rosa e de Walter George Durst e Walter Avancini (mini-série, TV); "Deus e o Diabo na Terra do Sol", de Glauber Rocha; "El llano en llamas", de Juan Rulfo; contos como "La siesta del Martes", "Un día después del sábado" e "Candida Eréndira", de Gabriel García Márquez - o último adaptado por Ruy Guerra -, "Tigipio", de Herman Lima e Pedro Jorge de Castro, apenas para mencionar os mais próximos a nós, no momento.

\section{Os espaços da imensidão e da solidão}

O elenco de obras mencionado manifesta similaridades na concepçāo do espaço. Pensando nas articulaçōes propostas por Greimas para dar conta do campo semântico da /espacialidade/, verificamos que as obras citadas atualizam expansōes na dimensionalidade, preferencialmente na horizontal, seja na /lateralidade/: "larguíssimo", seja na /perspectividade/ "longuíssimo" (no cinema geralmente traduzido pela máxima profundidade de campo). Essa constante parece configurar uma concepção hiperbólica do espaço. As seqüências iniciais e finais de "Vidas Secas" (Filme = F) constituem um exemplo enfático do que apontamos. Na abertura do filme aparecem em quadro apenas duas imensas faixas horizontais: céu e caatinga homogeneizados pela luz chapada. Não há nenhum ator. Lentamente, distinguimos um ponto vindo da máxima profundidade de campo ("longuíssimo") em direção ao espectador. Do grande plano geral/GPG, passamos ao de conjunto/PC, ao plano médio/PM e ao plano americano/PA. O ponto vai adquirindo forma humana ate distinguirmos Fabiano e os seus. $O$ que se perde na sucessão dos enquadramentos em termos de lateralidade e de perspectividade, se ganha em termos de proximidade (=identidade dos atores). No final do filme, ocorre o percurso inverso, começando com os retirantes em PA, de lado, para irem se afastando, de costas, diminuindo, diminuindo, até sumirem em máxima profundidade de campo enquanto a caatinga e o céu se estendem de novo diante de nossos olhos ("larguíssimo"). 
Os textos mencionados evidenciam que, em momentos fundamentais da narrativa e independentemente das coberturas lexemáticas/imagéticas (sertāo, caatinga, "llano", "desierto", "playa"...), as representaçōes do espaço se caracterizam pela imensidao (lembramos de "Grande Sertăo..."). A expansão hiperbólica é manifesta através dos mais variados recursos filmicos tais como grande angular, enquadramento em GPG, movimentos de afastamento com cámera muito alta (grua/helicóptero), entre outros. A impressão de que o espaço $\varepsilon$ muito vasto $\epsilon$, em geral, acentuada pela / vacuidade/. Durante seqüencias inteiras ou em boa parte delas, náo aparecem atores humanos e nem seres elementares que possam direcionar o olhar do espectador. Esta representação básica em termos de espacialidade É, em geral, acompanhada pela "lentidāo" (ou o extremo oposto: uma pressa desesperada, sem rumo) em termos de temporalidade expressa por movimentos lentos da cámera ou dos atores, por vezes chegando à imobilidade. O enunciado de "Vidas Secas" (Livro=L,p.9) $\epsilon$ esclarecedor nesse sentido: " $E$ a viagem prosseguiu, mais lenta, mais arrastada, num silencio grande". Na transmutação filmica, a câmera se move muito pouco na caminhada inicial e os atores andam vagarosamente. No espaço assim representado de forma recorrente nos textos, um ator nāo humano prevalece quase sempre sobre os humanos, trazendo em algumas obras ecos dos mitos indígenas pré-colombinos: o SOL, atualizado direta ou metonimicamente (lembramos de "Deus e o Diabo na terra do sol", "Vidas Secas" e "El llano en llamas"). Nesse sentido, um outro parágrafo de "Vidas Secas" é revelador: "Fabiano tocou o braço da muIher, apontou o ceu, ficaram os dois aguentando a claridade do sol. Enxugaram as lágrimas... conservaram-se encolhidos, temendo que a nuvem se tivesse desfeito, vencida pelo azul terrivel, aquele azul que deslumbrava e endoidecia a gente". (p.12). O filme transmuta o trecho em suas sequiencias iniciais, mas em P \& B com uma luz muito chapada ("claridade"). A representaçăo do espaço caracterizado pela imensidāo e pela aridez, dominado pelo sol, ocorre geralmente na dimensão pragmática da narrativa. Trata-se de uma concepçáo de espaço constante quando se atualiza o ápice do não poder/não saber dos atores ou quando suas performances colocam em risco os objetos-valores essenciais dos programas narrativos (crenças, vida..) como poderemos observar nos exemplos subsequientes. Em "Tigipi6" (F), Matilde aguarda Heitor junto ao carro de bois desativado e à árvore seca, em frente à casa do pai a câmera subjetiva mostra o sertâo devastado pela seca que arruinou o pai, sem que ele ou Matilde nada pudessem fazer. Desse mesmo sertāo, surge Heitor, a cavalo, pronto para renegar Matilde que espera um filho seu. Em "Vidas Secas" (L e F) sinhá Vitória olha da janela para a caatinga devastada e o çu cheio de aves de arribação, sabedora de que nada poderá fazer para impedir uma nova retirada. Eréndira (F) olha para o deserto empoeirado com a desolação de quem sabe que percorrerá muitos caminhos similares prostituindo-se para pagar a dívida à avó. Nos momentos em que a auséncia de poder dos atores chega ao limite, a sua desaparição na imensidão do espaço parece ser a melhor forma de figurativizá-la, como no final de "Vidas Secas", já visto, e na fuga derradeira de Eréndira ao longo da praia ( $L$ e F). Por vezes a expansão na horizontalidade é acompanhada de outra expansão na verticalidade através do máximo afastamento da 
câmera alta enfatizando a grandeza do espaço e a pequenez dos atores (=não poder), como na tomada de helić́ptero afastando-se de Manoel e Rosa que correm sem rumo pelo sertão imenso no final de "Deus e o Diabo...". Em algumas seqüểncias, movimentos circulares da câmera tentam adequar ou submeter a imensidão do espaço a fraqueza ou desespero dos atores, como na queda do Menino mais Velho no início de "Vidas Secas" ou na cavalgada de Diadorim pelo sertão, após saber da notícia da morte de Joca Ramiro. Durante a cavalgada, a câmera gira como se tragasse o sertão e o céu crepuscular, dando a idéia de desvario ou tontura no impotente desespero de Diadorim. Dentre as performances dos textos, lembramos a luta de Fabiano com o Soldado Amarelo em plena caatinga ( $L$ e F), o duelo de Corisco e António das Mortes em "Deus e o Diabo..." em pleno sertão. Fabiano olha a caatinga devastada (L e F) antes de tomar coragem para matar Baleia. A avó de Eréndira (F) persegue e consegue capturar a neta e Ulisses que dela fugiam num caminhão em meio ao deserto, não sem antes mandar matar o fot6grafo, cúmplice dos namorados. No final dessa seqüência também há um afastamento em câmera alta, enfatizando a pequenez dos capturados e do morto no deserto árido e brilhante de sol, mas É outra sequiência do filme que nos conduz a uma das chaves de nossas reflexōes . A avó de Eréndira, sentada numa cadeira, em meio ao vazio e à canícula do deserto, está maquinando formas de recuperar a neta em poder dos monges e diz a um passante: "Soy una pobre mujer sola en la inmensidad del desierto". (L,p.123 e F). Repensando as características dos espaços analisados, bem como de outros apenas citados (Comala e Luvina de "El llano em llamas", por exemplo), nos damos conta de que a representação hiperb6lica do espaço em que ocorre a supremacia do sol sobre os atores humanos em momentos de risco do relato, figurativizam a radical solidão do homem americano em face do poder fatal da natureza (terra/sol) e da cultura (ator antagonista, o outro). Lembramos de obras como "El Laberinto de la Soledad", "Cien ańos de Soledad", bem como do discurso de García Márquez na recepção do Prêmio Nobel, significativamente entitulado "La Solitude de l'Amerique Latine" na traduçāo francesa. Essa forma de representação é prática recorrente no cinema latino-americano, quer se trate da transmutação de textos regionalistas clássicos, "Tigipio", quer se trate de "Vidas Secas", considerado regionalista, mas com inovaçōes que tornam a classificação imprópria (Bibliog. 7), quer, ainda, se trate de obras como "Eréndira", típicas do realismo mágico.

\section{A representação do espaço e a evolução tecnológica}

Como poderia o cinema latino-americano traduzir o realismo mágico ou o "deicídio" praticado por García Márquez e analisado por Llosa (Bibliog. 6) e que em termos de representação subverte todas as delimitaçōes logicas do espaço, sem passar por uma revolução similar à da literatura na forma de representar a espacialidade? Aparentemente, o cinema latino-americano nâo teve, ainda, a oportunidade de praticar essa revolução. Hoje, essa subversão parece mais viável na TV, infinitamente mais dinâmica e melhor equipada para resgatar/atualizar/suplantar as conquistas do realismo mágico, de forma que o texto literário e o filmico, 
finalmente, se reencontrem. Se isso ocorrer, há grande probabilidade de que a sofisticação técnica e a temporalidade voraz da TV acabem por criar concepçōes espaciais radicalmente diversas. "Armação llimitada", da Globo, pode ser um exemplo paradigmático da representação espacial mediatizada pela revoluçāo tecnológica já processada na televisẫo da América Latina. Nesse programa, a concepção do espaço é primordialmente resultado de ediçâo eletrônica, trucagens e efeitos sofisticados utilizados de maneira a não restarem praticamente vestígios de uma espacialidade concreta mediatizável pela câmera, objeto de nossas reflexōes nesse artigo.

\section{BIBLIOGRAFIA BÁSICA}

1. GARCIA MÁRQUEZ, G. - "Los funerales de la mamá Grande". B. Aires, Sudamericana, 1975.

2. - "La increble y trirte historia de la Candida Eréndira y de su abuela desabmada". Buenos Aires, Sudamericana, 1972.

3. - - "La Solitude de IAmerique Latine". In Nouvel Observateur, Paris, Jan. 1983, p. 60-61.

4. GIACOMAN, H. - Homenaje a G. Garcia Márquez". NY, Madrid, Las Americas Publishing Co. Inc., 1972.

5. LOPES, E. e PEÑUELA, E. - "O mito e sua expressão na literatura hispanoamericana". S. Paulo, Duas Cidades, 1982.

6. LloSA, Vargas - "Gárcia Márquez - Historia de un Deicidio". Barcelona, Monte Ávila, 1971.

7. PEŃUELA, E. - 'Duas Leinuras Semióticas". Sāo Paulo, Perspoctiva, 1978.

8. RAMOS, Graciliano - "Vidas Secas". São Paulo, Martins Editora, 1967.

9. RENIER, A. et alii - "Espace, représentation et sémiotique de larchitecture" Paris, Editions de Ia Villete, 1981.

10. XA VIER, Ismail - "Serıäo Mar". Sāo Paulo, Brasitiense, 1983.

11. Revista "Filme Cultura". Rio de Janeiro, Embrafilme/MEC, n- 43, 1984.

\section{FILMOGRAFIA BÁSICA}

"TIGIPIO", Cor, 35 mm, 1985. Direçâo: Pedro Jorge de Castro. Elenco: Regina Dourado, ZE Dumont, B. de Paiva.

“VIDAS SECAS", P \& B, 1962. Direçăo: Nelson Pereira dos Santos. Elenco: Átila Iório, Jofre Soares.

“CANDIDA ERENDIRA", Cor, 35 mm, 1985. Direçăo: Ruy Guerra. Elenco: Irene Papas, Cládia Ohana.

"GRANDE SERTĀO: VEREDAS", Cor, Mini-série, Globo. Rot: Walter George Durst. Direçåo: Walter Avancini. Elenco: Bruns Lombardi, Tarcisio Meira, Toni Ramos. Obs: Embora realizada para a TV, a obra foi incluída por utilizar técnicas cinematograficas e nāo televisivas de filmagem, conforme afirmaçóes dos proprios realizadores.

RESUMEN

¿Cuáles son las representaciones del espacio que se reiteran en textos filmicos y literarios de realizadores y escritores latino-americanos?

¿Qué tipo de evolución se nota en esos textos a lo largo del tiempo y cuales son los factores que la condicionam?

El articulo trae algunas reflexiones sobre esas preguntas. 